Original Research Paper

\title{
Impact Behavior of High Strength Concrete Slabs with Pozzolana as Coarse Aggregate
}

\author{
Mahmoud B.A. Alhasanat and Arabi N. Al Qadi \\ Department of Civil Engineering, AlHussien Bin Talal University, Ma'an, Box 20, Jordan
}

Article history

Received: 03-03-2016

Revised: 03-06-2016

Accepted: 14-06-2016

Corresponding Author: Mahmoud B.A. Alhasanat Department of Civil

Engineering, AlHussien Bin Talal University, Ma'an, Box 20, Jordan

Email:mbh@ahu.edu.jo

\begin{abstract}
This research goal is the adding of pozzolana as rough aggregate in concrete. Pozzolans of Jabl Onyzh have been described as the major supply from Jordan. It is often used in the place of a conservative aggregate in frivolous concrete. A practical examination was carried out on the resistance of Pozzolana Lightweight Concrete (PLWC) with diverse ratios (35 and $50 \%$ ) of pozzolana from the whole size of admixture order to ascertain its impact. In this study, a design mix was used with several A mix design was determined through various experimental mixtures to make certain that the pozzolanas lightweight concrete will be able to attain the needed fundamental performance. A self-fabricated was used to simulate a low-velocity projectile effect on the slab specimens was aroused with the use of a self-invented drop-weight impact test rig. Twofold factors were examined to determine the impact resistance on slab $(300 \times 300 \mathrm{~mm})$ with diverse viscosity $(20,25$ and $30 \mathrm{~mm})$ support, with pozzolana content and concrete thickness. The impact resistance of concrete decreases with the addition of pozzolana but progresses with slab thickness. However, the influence is more prominent for the final crack resistance than for the first crack resistance. When slab thicknesses were compared with each other, the outcome was that $25 \mathrm{~cm}$ has a general superior performance in lightweight concrete for impact resistance.
\end{abstract}

Keywords: Pozzolana, Coarse Aggregate, Impact Strength, Impact CrackResistance, Ultimate Crack, Concrete Slab

\section{Introduction}

Several economic and structural benefits have been derived from the establishment of lightweight concrete. Lightweight concrete decreases the overall dead load of a structure, which guarantees the reduction of the structural members size of with the contribution and preservation of structural performance.

According to Webinar PCA (2010), for over centuries, a normal pozzolans have been in usage. "Pozzolan" is a term derived from the volcanic ash mined at Pozzuoli, a neighboring town of Naples in Italy, after the $79 \mathrm{AD}$ outburst of Mount Vesuvius. Nevertheless, ash and calcined clay have been in use as far back as $2000 \mathrm{BC}$ but in earlier use compared to other cultures. Several people such as the Roman, Greek, Indian and Egyptian pozzolan concrete structures are still available until and this confirms their strength and stability. The first time that the North America started experiencing natural pozzolans can be traced to early 20th century civic works projects, like dams and it was meant for increases of temperature regulating in mass concrete and gives cementitious material. Apart from regulating the increases of the temperature, natural pozzolans also helped for enhancing resistance to sulfate attacks and was equally regarded as one of the foremost materials to be found to mitigate alkali-silica reaction.

Abu-Snoubar and Abdel-Hafeth (2006); showed certain significant facts about pozzolana or volcanic tuff being a type of pyroclastic rocks created by the gatherings and deposition of solid materials; ejected from volcanoes. It is the lightweight, vesicular texture and a grain size less than $32 \mathrm{~mm}$ of these materials that described them. Pozzolana was first used as a word after it was discovered in the Pozouli area in Italy. Generally, these pyroclastic rocks include the following three sets: Agglomerate, is circular to sub- circular, $32 \mathrm{~mm}$ size pieces; breccia, is of the same size, but has an angular 
shape; and volcanic tuff, comprises volcanic pebbles and ash of diverse shapes and sizes.

According to ACI 232.1R-00 (2005), natural pozzolans cause an increase in the cohesive mixture and create a more plastic paste which enables the concrete to unite readily and run spontaneously in vibration. Segregation is diminished with the amplified. All natural pozzolans ought to possess some visible features which enable the Portland cement-pozzolan paste to comprise a full amount of solid matter and a least amount of water. This however helps the mineral particles not to possess high of a surface area. The ideal figure would be a smooth, round particle rather than an irregular, rough-textured particle that would have a higher water demand. An increased water demand of bentonite, with an external area which is significantly higher than cement, places restrictions on the actual capacity of usage that the natural pozzolana possesses, to smaller proportions than for those used in conventional concrete mixture proportions.

As Shannag (2000) has rightly pointed out, some workable high, to very high strength mortars and concretes have been created by using several mixtures of a local natural pozzolana and silica fume. Additionally, such mixtures have been verified for workability, density, compressive strength, splitting tensile strength and modulus of elasticity. It was recommended by the outcome that some natural pozzolana-silica fume mixtures have the capacity to enhance the compressive and severe tensile strengths, workability and flexible modulus of concretes; far beyond the natural pozzolana; and silica fume only. In addition, the usage of silica fumes yields the maximum strength. Using pozzolana at the same time alongside with silica fume results in the production of high strength concrete; and offers technical and commercial benefits in particular local uses in the concrete industry.

Alan and Smith (2009); have equally stressed some of the advantages, as well as the profits that can be from pozzolana. They are identified as the following: Lithification, auto-genus healing, abridged permeability and voids, brings about expansion reduction hydration heat, creep and cracks reduction, micro-cracking reduction, increased compressive strength, increased resistance to chloride attacks, reduced alkali-aggregate reaction, protected steel reinforcement from corrosion, increased abrasion resistance and depressed water necessity with high volatility, self-leveling and compression.

Al Qadi et al. (2014) investigated the resistance of OPS lightweight concrete effects with a geo grid. A mix scheme was ascertained with the use of several experimental mixes to guarantee the fact that the OPS lightweight concrete might reach the necessary structural performance. The Three following parameters have been experimented for resistance impact on both the specimens that have or do not have geo-grid reinforcement: (1) OPS content, (2) geo-grid types and (3) geo-grid layers. When geo-grid types where compared, there was an indication that geo-grid 80/80 has a general superior performance in lightweight concrete for resistance impact.

This study objectives are based on using pozzolana as a substitute aggregate in lightweight concrete and identifying the effect and crack resistance of highstrength pozzolana lightweight concrete slabs; with diverse slab thicknesses.

\section{Methods and Materials}

\section{Materials Used}

The materials used for this study consist of the Ordinary Portland Cement (OPC) as obtainable in the local market. The cement used was experimented for several percentages as per an ASTM C150 (ASTM 2006). 3.15 was the particular gravity of the cement while $4030 \mathrm{~cm}^{2} / \mathrm{g}$ was the Blaine fineness. The fine aggregate comprised river sand with a minimal size of $4.75 \mathrm{~mm}$, with a modulus of fineness of 3 and the sand content is $1127.57 \mathrm{~kg} / \mathrm{m}^{3}$. 2.5 was the particular magnitude while $0.86 \%$ was the absorption value. 1.6 is the particular gravity of pozzolana coarse aggregate while $7.7 \%$ is the absorption. The magnitude of the aggregate gradation of the pozzolana was not as much as $10 \mathrm{~mm}$ which performed for the pozzolana in order to guarantee the worth of the mix design. 0.5 equal was fixed ratio of the Water-to-Cement $(\mathrm{W} / \mathrm{C})$; the content of the cement is $320 \mathrm{~kg} / \mathrm{m}^{3}$, but $0.8 \%$ is the superplasticizer of the weight of the content of the cement, while pozzolana of 35 and $50 \%$; of the entire size was included as aggregate substitute in the mix design (Table 1). The pozzolan applied in the study stated as reported in this paper for fortification is $35 \%$ of the entire size of a compressive strength which is $40.41 \mathrm{MPa}$ and $50 \%$ by the overall volume of the mixture with a compressive strength is $37.45 \mathrm{MPa}$. The Silica Fume (SF) used in the design mix was an average of five percent.

\section{Preparation and Testing of Specimens}

Water was used to remove dirt and other unwanted materials like dust, etc from the pozzolanas and were allow to dry for some time before it could be used as aggregates in the concrete mixture were. Additionally, some water used to first soak the pozzolanas and was mixed thereafter. Its power of absorption however led to the saturation of the surface while it was being mixed and also results in workability decline. Also, in order to prevent dirt from entering, which affected the properties of the concrete mixture, the other material, was set aside in a dry and clean place to avoid any dust materials. 
Table 1. Mix proportion of pozzolana lightweight concrete

\begin{tabular}{lllllll}
\hline Mix number & $\begin{array}{l}\text { Cement } \\
\mathrm{Kg} / \mathrm{m}^{3}\end{array}$ & $\begin{array}{l}\text { Water } \\
\mathrm{Kg} / \mathrm{m}^{3}\end{array}$ & $\begin{array}{l}\text { Sand } \\
\mathrm{Kg} / \mathrm{m}^{3}\end{array}$ & $\begin{array}{l}\text { Silica fume } \\
\mathrm{Kg} / \mathrm{m}^{3}\end{array}$ & $\begin{array}{l}\text { Supper } \\
\text { plasticizer } \mathrm{Kg} / \mathrm{m}^{3}\end{array}$ & $\begin{array}{l}\text { Pozzolan course } \\
\text { aggregate } \mathrm{Kg} / \mathrm{m}^{3}\end{array}$ \\
\hline 1 & 320 & 214.89 & 1127.57 & 16 & 2.56 & $586.95(35 \%)$ \\
2 & 320 & 234.26 & 1127.57 & 16 & 2.56 & $838.51(50 \%)$ \\
\hline
\end{tabular}

Plywood was used to make the formwork for the concrete slab and was equally furnished to be reattachable in the case of more usage. To prevent an unequal slab surface, the formwork surface was smoothened. The formwork was coated using a layer of grease to ease the detachment of the concrete slab after hardening, before the mixed concrete was cast. New Concrete property slump test measurements were used to detect differences in the pozzolana lightweight concrete mixture cohesiveness.

The concrete mixture has to reach stability features in a situation in which the concrete is intact and maintains symmetrical form. Measurement of the compaction factor determined the extent of compaction coming out of the application of an average volume of work. The pozzolana concrete slab was cast only on one occasion and that was by the time all the materials were ready and the workability was suitable.

The pozzolana concrete mixture was transferred into the built formwork. For test specimens, the first layer of the mixture was dispensed and placing followed immediately. At that point, the second layer of the mixture was placed on the earlier layer to cover the formwork. The degree of fortification was arranged according to the specimens' tests.

In order to limit the air voids within the mixture, selfcompaction was performed. The casting of the pozzolana concrete slab followed for the next $24 \mathrm{~h}$ and then treated and preserved in a water pan at $22 \pm 1^{\circ} \mathrm{C}$ to the testing day. The test specimens curing was done as soon as the pozzolana concrete slab had toughened. The slab was then kept in a tank of water at $20^{\circ} \mathrm{C}$ for curing purposes, after it was separated from the formwork. The test specimens had to be removed for more experimenting after being were cured for 28 days. Figure la-d shows the stages of preparation and testing of the pozzolana lightweight concrete slab.

\section{Hardened Concrete Tests}

Based on the description of the slab specimen, all the slab specimens comprised the dimensions such as: 300 $\mathrm{mm}$ (width) $\times 300 \mathrm{~mm})$ breadth $(\times 20,25$ and $35 \mathrm{~mm})$ height). Up to the two percentages previously stated in this research, $(0.35$ and $0.5 \%)$ amounts of pozzolanas were further added to the concrete slabs for experimenting and determining the impact of the Pozzolanas on cracking. The effects of diverse layers of thicknesses of pozzolana lightweight concrete on crack control were tested.

\section{Data Analysis}

A fabricated test rig which comprises two components was used for impact testing. They are: (1) A steel rack with a steel channel which enables a drop weight to roll from it and (2) a slab holder table for the test specimen. The test specimen will be placed into the space on the support and placed following the steel rack. The impact load was laid open to the center of the slab. The steel ball (drop-weight projectile) was let down at a height of $1,000 \mathrm{~mm}$. Once the slab specimen and the drop weight are in position, the steel ball was free and permitted to free-fall onto the slab specimen. A good surveillance was made to identify the introduction of the first crack and the final crack. For the impact testing data acquisition, there was a cleanup of the specimen surface in order to ease the crack surveillance procedure in the impact testing. The various phases of the introduction of crack are documented as follows: The number of blows needed to start the crack was documented, until there was failure, which was documented as well. With the crucial failure, the whole crack length, width and depth have been documented. The ultimate crack resistance $R u$ is measured as Equation 1:

$R u=\frac{N e}{L c d c W c}$

Where:

$N=$ The number of blows

$e=$ Energy $(\mathrm{J})$ per blow

$l c=$ Total length of all cracks

$d c=$ Maximum crack depth

$w c=$ Maximum crack width

Equation 1 is established on the equation recommended by Kankam (1999). The ultimate crack resistance of the mortar slab specimens was measured with the use of Equation 1. The crack resistance ratio $\mathrm{Cr}$ is measured with the use of Equation 2:

$C r=R u f c u$

Where:

$\mathrm{Cr}=$ Impact crack resistance ratio

$F c u=$ Cube compressive strength of the reference mortar in $\mathrm{MPa}(1: 3 ; 70.7 \times 70.7 \times 70.7 \mathrm{~mm}$ Kankam, 1999) 


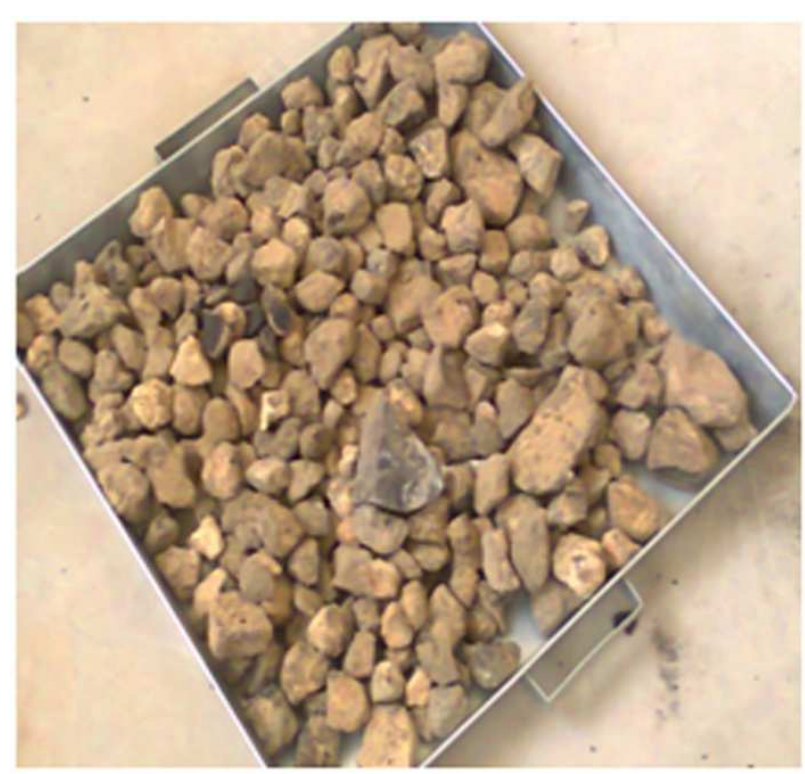

(a)

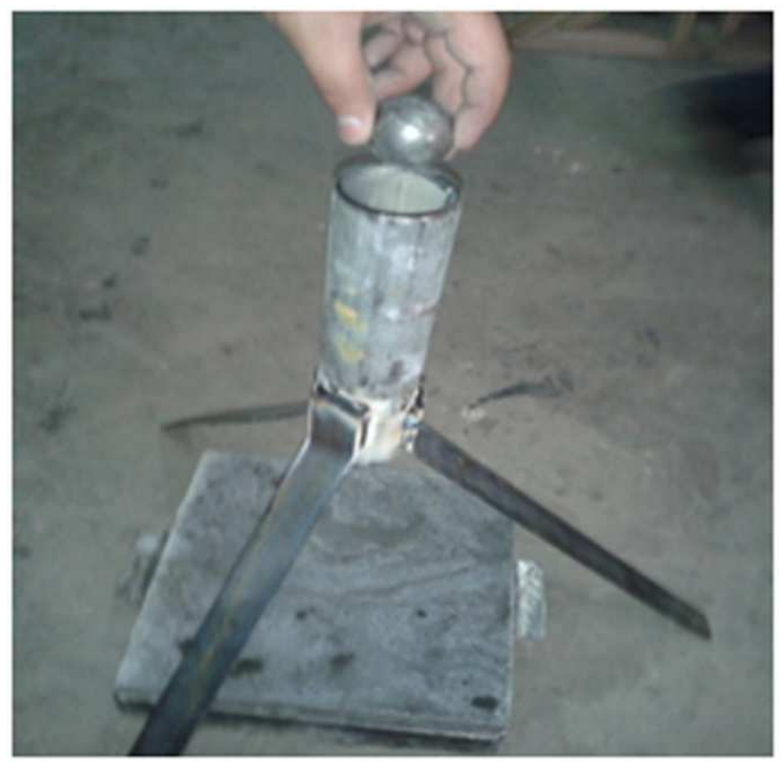

(b)

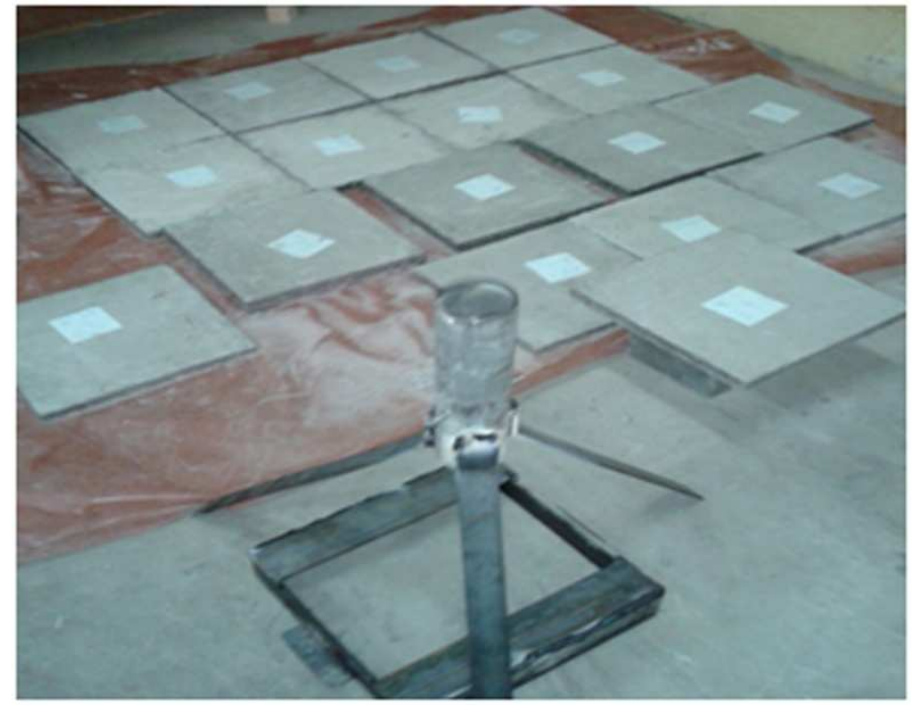

(c)
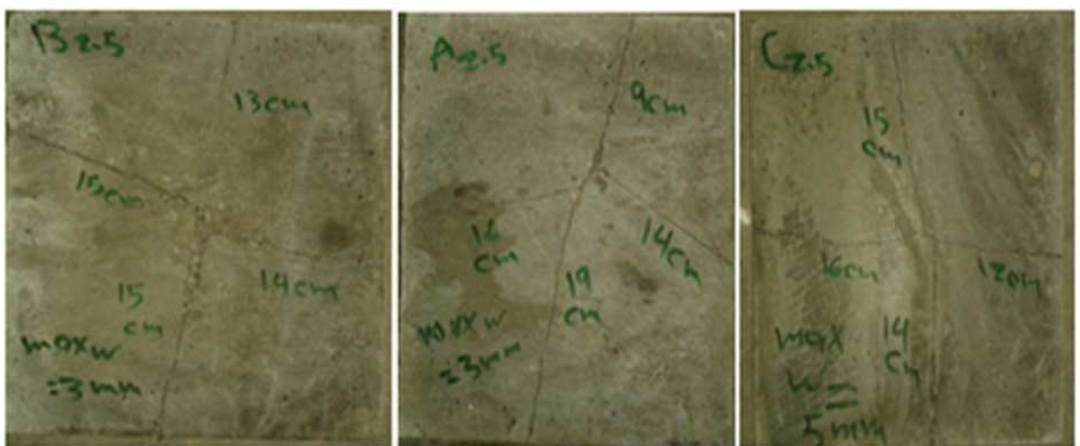

(d)

Fig. 1. Stages of the preparation and testing of Pozzolana lightweight concrete slab; (a) Pozzolana; (b) Free falling device; (c) Impact preparation test; (d) Slabs after impact test 


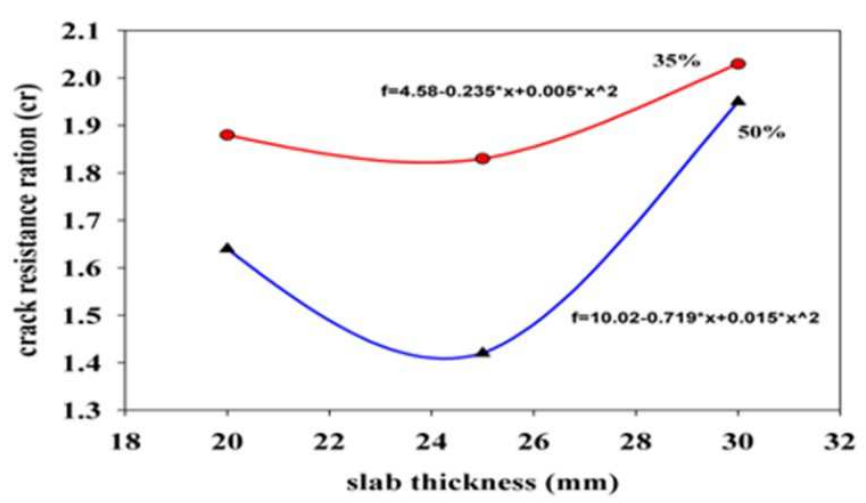

Fig. 2. Relationship of crack resistance ratio and slab thickness with $35 \%$ and $50 \%$ pozzolana coarse aggregate

Table 2. Maximum crack width and length, ultimate crack resistance and crack resistance ratio of slabs thickness with Pozzolana lightweight concrete

\begin{tabular}{lllllll}
\hline $\begin{array}{l}\text { Sample } \\
\text { number }\end{array}$ & $\begin{array}{l}\text { Pozzolana } \\
\text { Content ratio }\end{array}$ & $\begin{array}{l}\text { Slab Thickness } \\
(\mathrm{mm})\end{array}$ & $\begin{array}{l}\text { Maximum crack } \\
\text { width }(\mathrm{mm}) \mathrm{WL}\end{array}$ & $\begin{array}{l}\text { Maximum crack } \\
\text { length }(\mathrm{mm}) \mathrm{Lc}\end{array}$ & $\begin{array}{l}\text { Ultimate crack } \\
\text { resistance }\left(\mathrm{N} / \mathrm{mm}^{2}\right) \mathrm{Ru}\end{array}$ & $\begin{array}{l}\text { Crack resistance } \\
\text { ratio Cr }\end{array}$ \\
\hline 1 & 0.50 & 30 & 5.33 & 57.50 & 48.90 & 1.95 \\
2 & 0.50 & 25 & 3.67 & 57.33 & 35.67 & 1.42 \\
3 & 0.50 & 20 & 4.33 & 67.17 & 41.10 & 1.64 \\
4 & 0.35 & 30 & 4.67 & 46.17 & 56.26 & 2.03 \\
5 & 0.35 & 25 & 4.20 & 59.67 & 49.49 & 1.83 \\
6 & 0.35 & 20 & 4.00 & 49.75 & 50.64 & 1.88 \\
\hline
\end{tabular}

For the crack resistance, length, width, depth and energy absorption have been applied as parameters. Based on the survey recorded in this study, some apparatus (meter or ruler) was used to calculate the crack length, whereas the crack depth is presumed to be a constant $15 \mathrm{~mm}$ for all the specimens (Table 2) Fig. 2 presents the crack resistance of the various specimens. The crack resistance was due to the varying crack depth developed along the crack length.

\section{Results and Discussion}

\section{Impact Resistance}

Table 2 and Fig. 2 present the fresh data examined documented from the drop-weight impact test rig for the specimens with 35 and 50\% pozzolana uneven aggregate in pozzolana lightweight concrete. The amount of blows needed to start the first crack was virtually similar to each other for 35 and $50 \%$ pozzolana uneven aggregate. The amount of blows was not much different, but still indicated a pattern that specimens with lower than 35\% PLWC content needed the maximum amount of blows to start the first crack when in comparison to the specimens that had greater than $50 \%$ PLWC content. Additionally, the same was applicable for the number of blows needed to effect critical failure. Nevertheless, when compared, all the specimens are with different pozzolana percentages. Another surveillance was that by adding a $50 \%$, pozzolana massively diminished the amount of the needed blows to effect crucial failure in Specimens 2-3. For the crack width and length which was an outcome of the impact energy, the results presented a unsystematic arrangement of data. For the duration of the experimental surveillance, cracks promulgated haphazardly from the middle of the test specimen outward to the brink of the specimen. As a result of ignorance concerning crack propagation, the obvious randomness of the data could not be explained. Nonetheless, there is a probability that a component of the mixture triggered the randomness. The diverse sizes of the pozzolana might have instigated the pressure to travel in diverse manners every time the impact load was used. Table 2 presents the association of the amount of blows when compared to the percentage of pozzolana. The regression model presents the linearity between the number of blows and the pozzolana-to-cement ratio in Fig. 2. This pointed out that a correlation coefficient $\left(\mathrm{R}^{2}\right)$ is nearly equal to 1.0 for the curve of the crack and nearly equal to 1.0 for the crucial crack, which shows a goodness-of-fit for the data.

\section{Crack Resistance}

Table 2 and Fig. 3 present the crack resistance of each specimen for both the first crack instigation and crucial failure. Even though crack resistance had a related arrangement, yet there was still some irregularity within the outcomes. Considering the individual specimens, $35 \%$ pozzolana had a critical crack resistance of $56.26 \mathrm{~N} / \mathrm{mm}^{2}$ which was higher than that for the crack 
resistance of the $50 \%$ pozzolana. The irregularity could be linked to several factors. Considering the use of crack width as one of the parameters, as crack width is very challenging to distinguish by means of the naked eye. Slim modifications in crack width judgment may affect the de-termination of crack resistance considerably. Additional factor that added to the irregularity was the total crack length; since each specimen had a different and unique crack length, the outcomes were less foreseeable. Even though the individual results did not show regularity, an average crack resistance for all specimens measured, the crack resistance were calculated and examined to offer a richer picture.

In understanding the crack behavior of the specimens, as the content of the pozzolana amplified, the crack resistance of the specimens declined. The regression model in Fig. 3 shows that the connection coefficient $\left(\mathrm{R}^{2}\right)$ was approximately equal to 1.0 for the curve of the $35 \%$ pozzolana crack and approximately equal to 1.0 for the crucial crack which shows a goodness- of-fit for the data.

\section{Failure Pattern}

From the experimental surveillance, there are two types of failure mode. For specimens with 35 and $50 \%$ pozzolana, at failure, the specimens broke into two pieces. For the duration of the initial impact loading, the crack improved along the middle of the specimens' bottom surface place. The specimens are freely reinforced only on two sides; hence, the impact energy was only able to travel via the reinforced sides. In addition, the pressure prompted at the unsubstantiated sides leads to crack development. For the specimens with $50 \%$ pozzolana, the specimens will crack first and then breakdown into two portions at crucial failure Fig. 4 and 5 present the first crack advanced for control specimen $35 \%$ pozzolana when under impact loading. The crack only advances in one way, which is usually the least-supported side. At beginning, the crack width is very fine (a hairline crack). All crack promulgations for the control specimens possess a related arrangement Fig. 4; only the crack length poles apart.

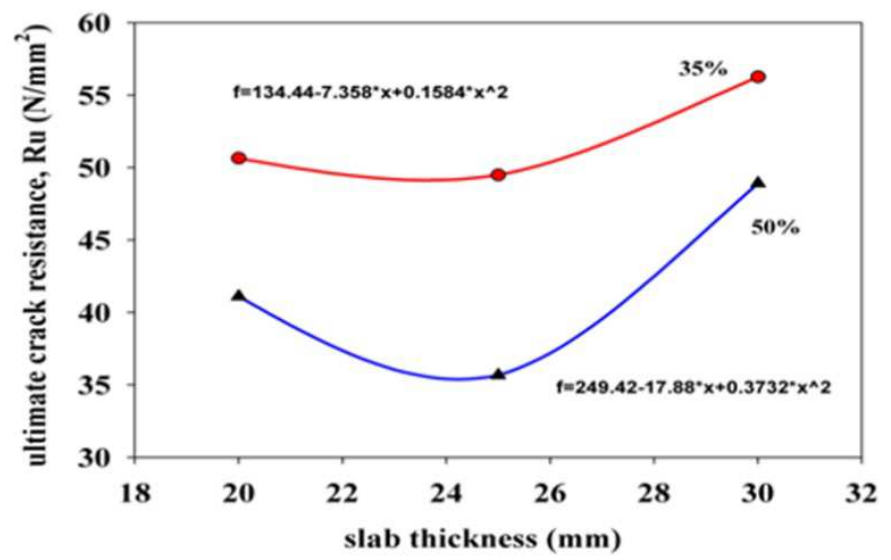

Fig. 3. Relationship of Ultimate crack resistance and slab thickness with 35 and 50\% pozzolana coarse aggregate

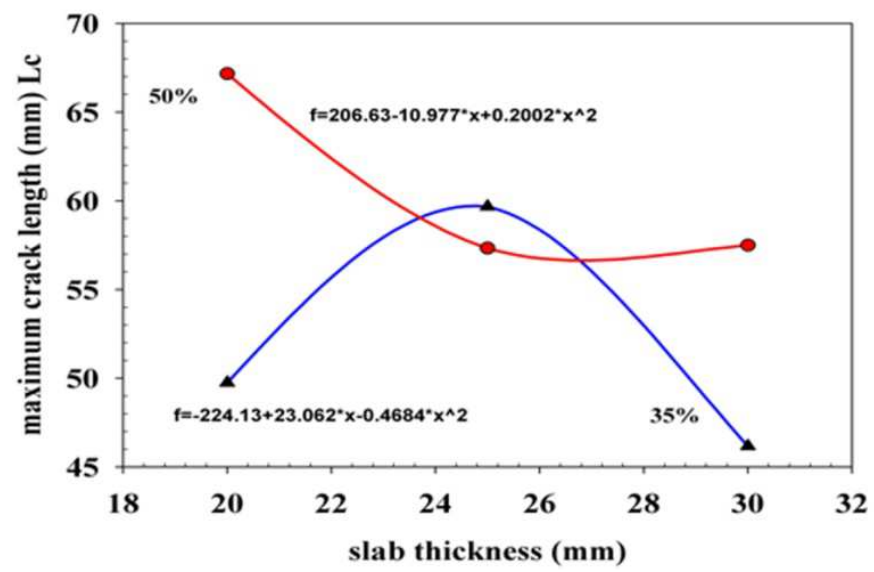

Fig. 4. Relationship of maximum crack length and slab thickness with 35 and 50\% Pozzolana coarse aggregate 


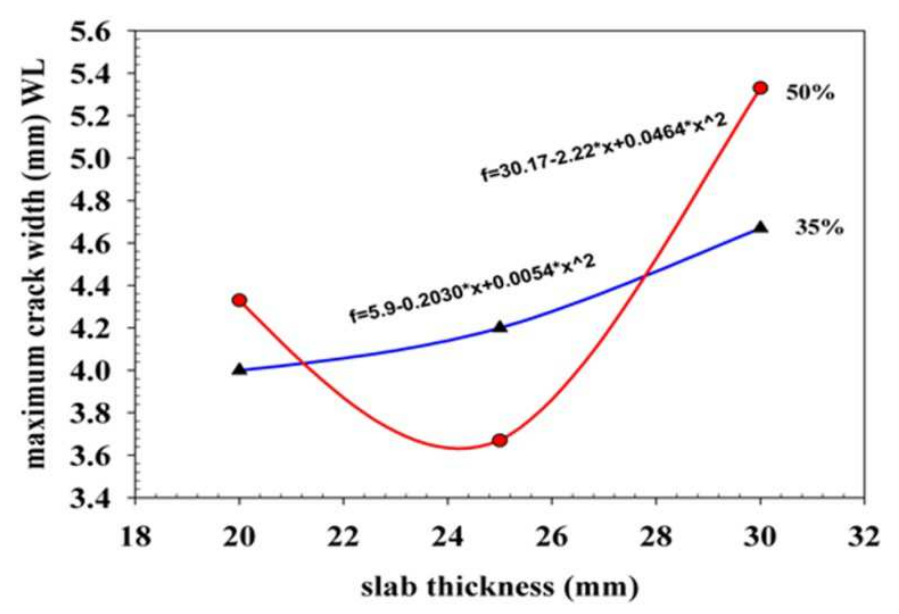

Fig. 5. Relationship of maximum crack width and slab thickness with 35 and 50\% pozzolana coarse aggregate

Further, Fig. 5 displays the failure mode for controlling the specimens of $35 \%$ pozzolana where it was divided into two segments. In the course of the experimental procedure, after the first crack was developed, the specimen began to deflect when under impact loading. But with two or three blows, the specimen fails at last with no fortification; the controlled specimen was unable to put up with more impact loading, therefore, it fails in a short period. Figure 5, also displays one more crack developed vertical to the failure crack. Once the cracked had developed, the concrete was no longer able to fight against more loading as there was no bonding at the crack area. As the impact loading persists, the impact energy has a tendency to travel from end to end of another direction, henceforward, the prompted pressure in the other direction and developed a crack.

\section{Conclusion}

The connection that exists between the crack resistance and test parameters are presented and analyzed. The pozzolana percentage effect on impact resistance, the percentages effect on impact resistance and effect on impact resistance all have diverse influences on the impact resistance, as identified below:

- A rise of pozzolana content adjusts the concrete slabs thickness of $25 \mathrm{~mm}$

- Addition of a slab thickness in the specimen reduces the crack resistance, for both the first crack and final disaster

- For the investigation of crack resistance and, the comparison of 35 and $50 \%$ pozzolana coarse aggregate as lightweight concrete gives a total better influence to crack resistance

\section{Acknowledgement}

The author would like to acknowledge Wala'a Mohammed Al Khatib, Anas Mohammed Al Ajaleen, Islam Mohammed Al Ajoleen and Ahmed Ezaldeen Abu Assal for their help in implementing this research at the Laboratories of Civil Engineering Department, Al Hussien Bin Talal University.

\section{Author's Contributions}

Mahmoud B. Alhasanat and Arabi N. S. Al Qadi participated in all experiments, data analyses and the writing of this manuscript.

\section{Ethics}

This article is original and contains unpublished material. The corresponding author confirms that all of the other authors have read and approved the manuscript and no ethical issues are involved.

\section{References}

Abu-Snoubar and Abdel-Hafeth, 2006. Evaluation of Tal Rimah pozzolana. JJES, 9: 33-49.

ACI 232.1R-00, 2005. Use of raw or processed natural pozzolans in concrete. Reported by ACI Committee 232, American Concrete Institute, Farmington Hills, Michigan.

Al Qadi, A.N.S., Q.N.S. Al-Kadi and S.M. Al-Zaidyeen, 2014. Impact strength of oil-palm shell on lightweight concrete slabs reinforced with a geo-grid. Am. Society Civil Eng., 27: 04014264-1-04014264-7.

DOI: $\quad 10.1061 /(A S C E) M T .1943-5533.0001142$, 04014264 
ASTM, 2006. Specification for ordinary Portland cement. C150, West 408 Conshohocken, PA.

Alan, J. and K.D. Smith, 2009. Commercial Drafting and Detailing. 3rd Edn., ISBN-10: 1111781818, pp: 608.

Kankam, C.K., 1999. Impact resistance of palm kernel fibre-reinforced concrete pavement slab. J. Ferrocement, 29: 279-286.
Shannag, M.J., 2000. High strength concrete containing natural pozzolan and silica fume. Cement Concrete Comp., 22: 399-406.

DOI: $10.1016 / \mathrm{S} 0958-9465(00) 00037-8$

Webinar PCA., 2010. Design and control of concrete mixtures. Webinar PCA. 